\title{
Hearing and vestibular rehabilitation, with a focus on the elderly
}

The increasing proportion of our patients in the 'elderly' age group in the developed world has effects on ENT as well as every other branch of medicine. In The Journal of Laryngology \& Otology in the recent past, we have looked at a variety of topics of particular interest to the otolaryngologist and geriatrician, including pharyngeal pouch, ${ }^{1}$ vestibular dysfunction and presbyacusis, ${ }^{2,3}$ and cochlear implantation. ${ }^{4}$ In this issue, an auditory brainstem response study focuses on the mechanism of hearing difficulty in the elderly, especially in noisy surroundings, comparing the elderly and young adults. ${ }^{5}$ This revealed significantly lower amplitudes and increased latencies in brainstem responses in the elderly, indicating that subcortical mechanisms are involved in this deficiency. With regard to the frequent need for vestibular rehabilitation therapies in the elderly, it is disappointing but perhaps not surprising that elderly males are apparently more likely to fail to complete vestibular rehabilitation programmes than their younger counterparts. ${ }^{6}$ Vestibular rehabilitation programmes may not be inexpensive, but bone-anchored hearing aids are an established and necessarily expensive aid to hearing impairment rehabilitation. The review paper from Manchester helps us to understand why the take-up of this technology is not always as high as might be hoped for. ${ }^{7}$ The authors call for much more evidence to help providers focus their efforts appropriately and to help patients take advantage of what could help them a great deal.

This issue of The Journal has papers on both adult and paediatric subglottic stenosis. Sharma and colleagues describe a decade of experience in balloon dilatation at Great Ormond Street Hospital, which has considerable advantages over open surgery in these challenging cases. ${ }^{8}$ These authors provide practical guidance on the technique based on 166 cases. Nicolli and colleagues, from Pennsylvania, describe a retrospective case-control study in adults, in which they identify obesity and diabetes mellitus as risk factors for the development of subglottic stenosis. ${ }^{9}$ These papers complement a paper from New Delhi published in 2014, which investigated the aetiology and management of subglottic stenosis. ${ }^{10}$

Ear trauma is a topic that is often neglected. Song et al. help redress this with a detailed study of patients with temporal bone fractures that spare the otic capsule. ${ }^{11}$ Happy reading!

\author{
EDWARD FISHER \\ ROBIN YOUNGS \\ MUSHEER HUSSAIN \\ JONATHAN FISHMAN \\ Senior Editors
}

References

1 Stewart K, Sen P. Pharyngeal pouch management: an historical review. J Laryngol Otol 2016;130:116-20

2 Tan JL, Tang J, Lo S, Yeak S. Investigating the risk factors of vestibular dysfunction and the relationship with presbyacusis in Singapore. J Laryngol Otol 2016;130:816-21

3 Luscher M, Theilgard S, Edholm B. Prevalence and characteristics of diagnostic groups amongst 1034 patients seen in ENT practice for dizziness. J Laryngol Otol 2014;128:128-33

4 Hilly O, Hwang E, Smith L, Shipp D, Nedzelski JM, Chen JM et al. Cochlear implantation in elderly patients: stability of outcome over time. J Laryngol Otol 2016;130:706-11

5 Ansari MS, Rangasayee R, Ansari MA. Neurophysiological aspects of brainstem processing of speech stimuli in audiometric-normal geriatric population. J Laryngol Otol 2017;131: 239-44

6 Soto-Varela A, Faraldo-García A, Del-Río-Valeiras M, RossiIzquierdo M, Vaamonde-Sánchez-Andrade I, Gayoso-Diz P et al. Adherence of older people with instability in vestibular rehabilitation programmes: prediction criteria. J Laryngol Otol 2017; 131:232-8

7 Powell R, Wearden A, Pardesi SM, Green K. Understanding the low uptake of bone-anchored hearing aids: a review. J Laryngol Otol 2017;131:190-201

8 Sharma SD, Gupta SL, Wyatt M, Albert D, Hartley B. Safe balloon sizing for endoscopic dilatation of subglottic stenosis in children. J Laryngol Otol 2017;131:268-72

9 Nicolli EA, Carey RM, Farquhar D, Haft S, Alfonso KP, Mirza N. Risk factors for adult acquired subglottic stenosis. J Laryngol Otol 2017;131:264-7

10 Pookamala S, Thakar A, Puri K, Singh P, Kumar R, Sharma SC. Acquired subglottic stenosis: aetiological profile and treatment results. J Laryngol Otol 2014;128:641-8

11 Song SW, Jun BC, Kim H. Clinical features and radiological evaluation of otic capsule sparing temporal bone fractures. J Laryngol Otol 2017;131:209-14 